\title{
Erica Flapan to Top Notices Masthead
}

\author{
SophiaD. Merow
}

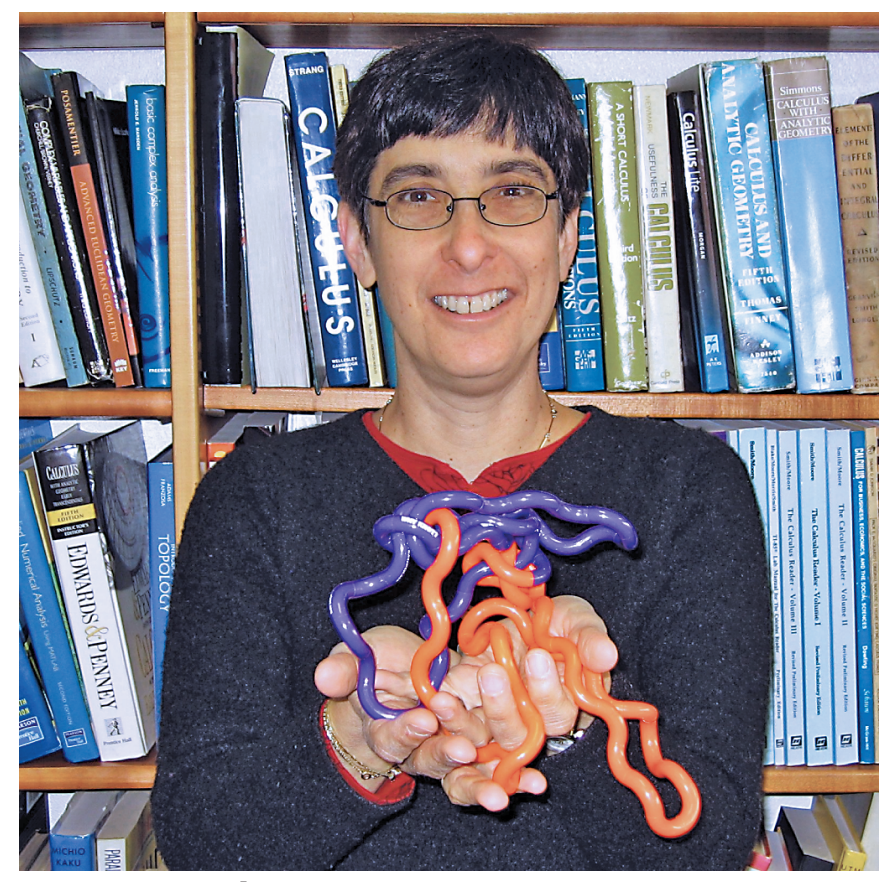

Incoming Notices editor Erica Flapan studies the rigid and flexible geometry of molecules.

Erica Flapan, the Lingurn H. Burkhead Professor in the Department of Mathematics at Pomona College, will begin a three-year term as editor of Notices starting with the January 2019 issue.

She's psyched.

Flapan gets a thrill when she proves a theorem or initiates a cohort of Pomona students into the mysteries of topology. But when she learned she'd be the next editor of Notices-and began thinking about what that would entail-Flapan felt a different kind of excitement.

"I think doing something new at my age is good," she says. "It's stressful but it's also very exciting to be learning

Sophia D. Merow is assistant to the Notices editor. Her email address is merow.notices@gmai1.com.

For permission to reprint this article, please contact: reprint-permission@ams .org.

DOI: http://dx.doi.org/10.1090/noti1748 something completely new and also communicating with people on a different level."

Flapan completed her undergraduate education at Hamilton College and earned her PhD under Daniel R. McMillan at the University of Wisconsin-Madison for a dissertation titled "Non-Periodic Knots and Homology Spheres." She was a post-doc at Rice and UC-Santa Barbara before joining the Pomona College faculty in 1986.

Flapan works in spatial graph theory, the area of topology that studies knots embedded in $S^{3}$ and other 3 -manifolds. She is particularly interested in symmetries of non-rigid molecules and the role that knotting plays in DNA recombination and protein folding. She relishes working in an area that is "simultaneously very pure and also applied."

Flapan's CV lists 56 research papers and five books, three of which were published by the AMS (see Figure 1). She won the Mathematical Association of America's Deborah and Franklin Tepper Haimo Award for Distinguished College or University Teaching of Mathematics in 2011 and was named an inaugural Fellow of the AMS in 2012. She spent eleven summers as an instructor at Carleton College's Summer Math Program, and from 2015 to 2017 traveled the country giving talks as MAA Pólya Lecturer. Her service to the AMS includes stints on the Committee on Education, the Committee on Professional Ethics, and the editorial committee of the Student Mathematical Library, and as a Member at Large of the Council.

Flapan sees membership in the AMS as an identity matter, not a question of the tangible benefits reaped by forking over annual dues. "I see the AMS as the organization that represents mathematicians who are actively doing mathematics. I think that every mathematician who is interested in research should want to be a member of the AMS and be part of shaping its future."

"The Notices is the best way that the AMS has to communicate with its members and potential members," says Flapan. "The Notices has the potential to reach out to a broader audience of mathematicians so that they feel that the AMS speaks to their interests, and hence they will become motivated to join."

Besides experience wrangling colleagues into producing quality mathematical content (see, again, Figure 1), Flapan boasts other characteristics bound to prove useful 


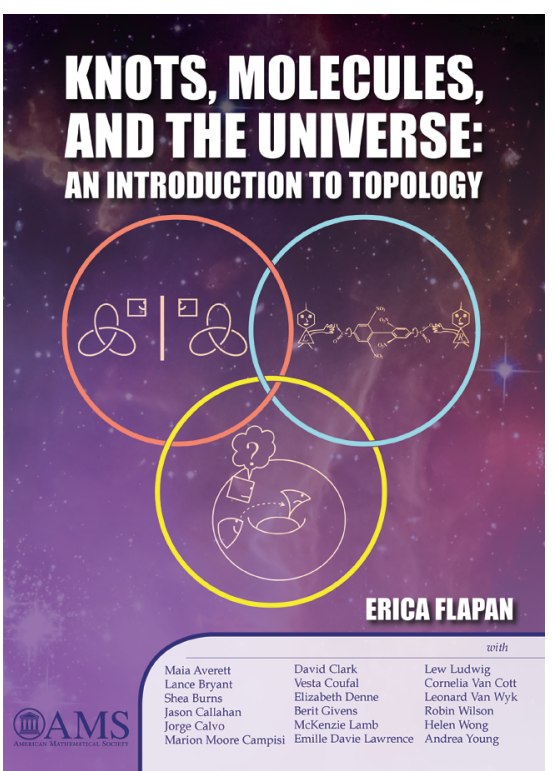

Figure 1. As leader of the Undergraduate Faculty Program at the Park City Mathematics Institute in 201 , Flapan was charged with guiding a group of faculty to collaboratively produce materials that could be used at a broad range of institutions. The resulting volume has 18 coauthors! have taken place in national laboratories and agenciesand an Early Career Section. Spearheaded by Angela Gibney, the Early Career Section will give graduate students, postdocs, and tenure track faculty access to the accrued wisdom of their mathematical forebears.

"It's completely different from anything that's been in the Notices before," says Flapan.

Flapan wants the experience of writing for Notices to be interesting and satisfying, and hopes authors will enjoy crafting content for the publication's wide audience. Flapan is encouraging individual authors to write in their own styles and thinks readers will benefit from the diversity that will no doubt result.

"I want readers to go in with the mindset that there's going to be a variety of articles," she says, "and hopefully there will be something you find interesting and will be at a level or in a style that you really appreciate."

\section{Image Credits}

Photo of Erica Flapan courtesy of Stephan Garcia.

Figure 1 courtesy of the AMS.
FEATURED TITLES FROM THE

EUROPEAN

MATHEMATICAL SOCIETY

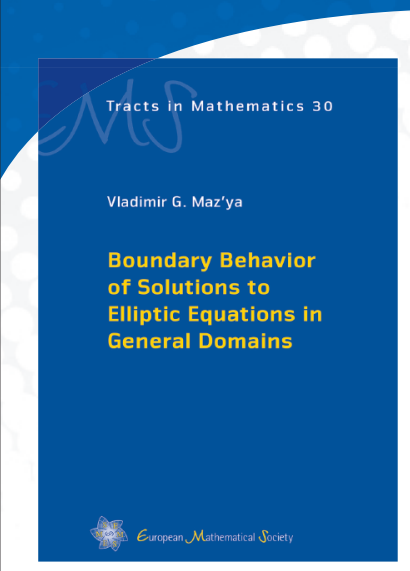

Boundary

Behavior of

Solutions to

Elliptic Equations

in General

Domains

Vladimir G. Maz'ya, Linköping University, Sweden, and University of Liverpool, UK

This book is a detailed exposition of the author and his collaborators' work on

boundedness, continuity, and differentiability properties of solutions to elliptic equations in general domains, that is, in domains that are not a priori restricted by assumptions such as "piecewise smoothness" or being a "Lipschitz graph".

EMS Tracts in Mathematics, Volume 30; 2018; 441 pages; Hardcover; ISBN: 978-3-03719-190-3; List US\$98; AMS members US\$78.40; Order code EMSTM/30

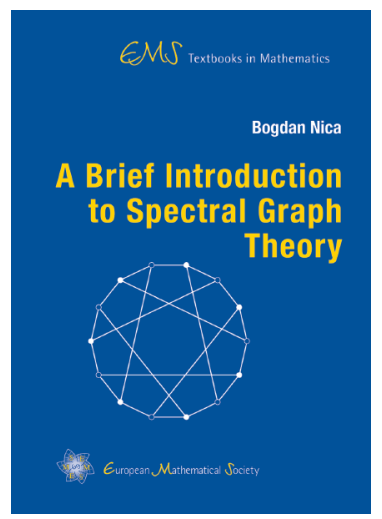

\section{A Brief Introduction} to Spectral Graph Theory

Bogdan Nica, McGill University, Montreal, Canada

This text is an introduction to spectral graph theory and can be used as an invitation to algebraic graph theory.

EMS Textbooks in

Mathematics, Volume 21; 2018 168 pages; Hardcover; ISBN: 978-3-03719-188-0; List US\$48; AMS members US $\$ 38.40$; Order code EMSTEXT/21

\section{Explore more titles at} bookstore.ams.org.

Publications of the European Mathematical Society (EMS). Distributed within the Americas by the American Mathematical Society.

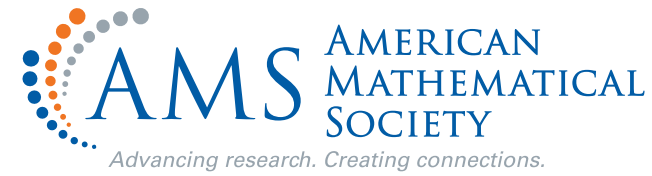

